\title{
Efficacy of levofloxacin versus cefuroxime in treating acute exacerbations of chronic obstructive pulmonary disease
}

This article was published in the following Dove Press journal:

International Journal of COPD

9 July 2013

Number of times this article has been viewed

\author{
Ho II Yoon' \\ Chang-Hoon Lee ${ }^{2}$ \\ Deog Kyeom Kim ${ }^{3}$ \\ Geun Min Park \\ Sang-Min Lee ${ }^{2}$ \\ Jae-Joon Yim² \\ Jae-Yeol Kim ${ }^{5}$ \\ Jae Ho Lee' \\ Choon-Taek Lee' \\ Hee Soon Chung ${ }^{3}$ \\ Young Whan Kim ${ }^{2}$ \\ Sung Koo Han ${ }^{2}$ \\ Chul-Gyu Yoo²
}

'Division of Pulmonary and Critical Care Medicine, Department of Internal Medicine and Lung Institute, Seoul National University Bundang Hospital,

Seongnam-si, Republic of Korea; 2Division of Pulmonary and Critical

Care Medicine, Department of Internal

Medicine and Lung Institute, Seoul

National University College of Medicine,

Seoul, Republic of Korea; ${ }^{3}$ Division of

Pulmonology, Department of Internal

Medicine, Seoul National University

Boramae Hospital, Seoul, South Korea;

${ }^{4}$ Division of Pulmonology and Critical

Care Medicine, Department of Internal

Medicine, Dongguk University Ilsan

Hospital, Dongguk University College

of Medicine, Goyang, Republic of Korea;

${ }^{5}$ Division of Pulmonary and Critical

Care Medicine, Department of Internal

Medicine, Chung-Ang University College

of Medicine, Seoul, Republic of Korea

Correspondence: Chul-Gyu Yoo

Division of Pulmonary and Critical

Care Medicine, Department of

Internal Medicine and Lung Institute,

Seoul National University College of

Medicine, 101 Daehak-ro, Jongno-gu,

Seoul I 10-744, Republic of Korea

Tel +82220723760

$\mathrm{Fax}+8227629662$

Email cgyoo@snu.ac.kr
Background: Antibiotic treatment is one of the major pharmacologic treatments for acute exacerbation of chronic obstructive pulmonary disease (AECOPD). However, the choice of antibiotic depends on the local resistance pattern. A multicenter, randomized, controlled trial was done in patients with AECOPD to compare the efficacy of levofloxacin with that of cefuroxime axetil.

Methods: Patients with AECOPD and without radiographic evidence of pneumonia were enrolled and randomized to either levofloxacin $500 \mathrm{mg}$ daily or cefuroxime $250 \mathrm{mg}$ twice daily in the mildmoderate exacerbation group, or $500 \mathrm{mg}$ twice daily in the severe exacerbation group, for seven days. Clinical efficacy and microbiologic response were evaluated 5-7 days after the last dose. Results: Treatment was clinically successful in $90.4 \%$ of patients in the levofloxacin group, and in $90.6 \%$ of patients in the cefuroxime group (95\% confidence interval -9.40 to 10.91 ), within a noninferiority margin of $10 \%$. The microbiologic response appeared to be higher in the levofloxacin group, but the difference was not statistically significant. The safety profile was similar in both groups.

Conclusion: Levofloxacin is not inferior to cefuroxime with regard to clinical efficacy in treating AECOPD.

Keywords: chronic obstructive pulmonary disease, acute exacerbation, levofloxacin, cefuroxime

\section{Introduction}

Acute exacerbation of chronic obstructive pulmonary disease (AECOPD) is a serious event. It is related to decreased health status, increased medical and social costs, and increased mortality. ${ }^{1-3}$ The mainstay of pharmacologic treatment for AECOPD includes antibiotics and systemic steroids. ${ }^{4}$ Antibiotics have been shown to be beneficial in patients with increased or purulent sputum and in those with severe exacerbations requiring ventilatory support. ${ }^{5-9} \mathrm{~A}$ recent report showed that antibiotics in addition to systemic steroids in AECOPD have a short-term effect on clinical outcome and microbiologic success. ${ }^{10}$

However, the choice of antibiotic is a more complicated issue. Organisms frequently isolated from patient with AECOPD are Streptococcus pneumoniae, Haemophilus influenzae, Moraxella catarrhalis, so-called atypical pathogens, and respiratory viruses $^{11-16}$. In more severe exacerbations and in patients with risk factors, it is known that Pseudomonas aeruginosa and Enterobacteriaceae can be pathogenic organisms. ${ }^{17-21}$ Moreover, the prevalence of each pathogen can be different according to the regional microbiologic environment, so it is crucial to consider individual characteristics and 
regional prevalence of micro-organisms as well when choosing antibiotics in AECOPD. Drug resistance of S. pneumoniae is a serious issue in some countries. In Korea, for example, $60 \%-75 \%$ of isolates of $S$. pneumoniae show intermediate or high resistance to penicillin. Therefore, it is important to investigate if other antibiotics are as useful as conventional choices in some countries.

Levofloxacin is a fluoroquinolone antibiotic agent with activity against various micro-organisms causing AECOPD, and is widely recommended for the treatment of AECOPD, along with macrolides, combinations of $\beta$-lactam/ $\beta$-lactamase inhibitors, and second-generation or third-generation cephalosporins. Although widely used in clinical practice to treat AECOPD, ${ }^{22,23}$ the efficacy and safety of levofloxacin in comparison with other antibiotics is seldom investigated. Levofloxacin has been demonstrated to be effective and safe compared with cefuroxime in three randomized clinical trials, but the subjects in those studies were patients with chronic bronchitis, not COPD. ${ }^{24,25}$ Therefore, we designed a randomized clinical trial to investigate whether or not levofloxacin is inferior to cefuroxime with regard to its clinical efficacy and safety in the treatment of AECOPD.

\section{Materials and methods}

\section{Study design and patients}

This prospective, multicenter, randomized, open-label, parallel-group clinical trial was carried out at seven hospitals in South Korea from November 2006 to June 2009. In total, 141 men and women older than 18 years with AECOPD were enrolled. Exacerbation of COPD was defined as recently increased cough or dyspnea, recent change in color or amount of sputum, and a diagnosis of COPD on spirometry, ie, postbronchodilator forced expiratory volume in one second/ forced vital capacity $<0.7$.

Initial plain chest radiography was reviewed by two chest radiologists, and those patients who had radiographic evidence of pneumonia, bronchiectasis, cystic fibrosis, tuberculosis, or lung cancer were excluded. Patients with serious renal dysfunction, a history of seizure, a history of allergy or other side effects to quinolone, cephalosporins, or penicillins, a history of antibiotic therapy during the previous 48 hours, pregnancy or possibility of pregnancy, and lactating women were also excluded.

All patients were judged to have mild, moderate, or severe AECOPD by specialists, and randomized to receive levofloxacin or cefuroxime in a ratio of $1: 1$. A simple randomization was performed at the study coordinating center by a single person who was not otherwise involved in the study. A central computer was used to randomize patients stratified by site.

Patients in the levofloxacin group were treated with a once-daily dose of $500 \mathrm{mg}$ for seven days, and those in the cefuroxime group were treated for seven days with $250 \mathrm{mg}$ twice daily (mild to moderate exacerbations) or $500 \mathrm{mg}$ twice daily (severe exacerbations). All patients provided their informed consent, and the study protocol was approved by the local institutional review board for all hospitals.

\section{Outcomes and follow-up}

On the first return visit (3-5 days after the initial visit) and the second return visit 2 (5-7 days after final dose), all patients were evaluated for clinical response, side effects, and compliance with medication. Plain chest radiography was obtained at the initial visit, sputum for Gram stain and microbiologic culture was obtained at all visits, and laboratory tests for blood cell counts, serum chemistry, and urinalysis were also performed at the initial and second visits. Two sets of blood cultures were obtained at the initial visit for patients in whom bacteremia was suspected, and at subsequent visits in cases of proven bacteremia.

The primary outcome was clinical success of antibiotic therapy. Clinical response was graded as cure, improved, or failure, and a clinical response of cure and improved at the second visit were defined as clinical success. The secondary outcome was microbiologic efficacy. Microbiologic response was graded as eradication (disappearance of pathogenic bacteria on the second visit), presumed eradication (inability to produce sputum due to improvement), persistence (persistence of initial pathogenic bacteria), presumed persistence (detection of pathogenic bacteria only on the second visit with clinical evidence of persistence), or superinfection (appearance of pathogenic bacteria other than initial ones) at the second visit. A microbiologic response of eradication, presumed eradication, or superinfection was defined as effective.

\section{Statistical analysis}

Based on a previously reported clinical success rate of $75 \%$ for levofloxacin and $76 \%$ for cefuroxime, ${ }^{24}$ we estimated that 62 patients would be needed in each group to demonstrate that clinical success in the levofloxacin group was not lower than $10 \%$ compared with the cefuroxime group, with a statistical power of $80 \%$. Therefore, we enrolled 70 patients in each treatment group, assuming a $12 \%$ dropout rate.

We used SAS version 9.1.2 (SAS Corporation, Cary, $\mathrm{NC}, \mathrm{USA}$ ) for data management and statistical analysis. The 
lower limit of the $95 \%$ confidence interval for a difference in clinical success (success rate of levofloxacin group - success rate of cefuroxime group) of $-10 \%$ was defined as the criterion for noninferiority. The intention-to-treat population was used for all analyses. The clinical success rate in the two groups was compared by Chi-square test.

\section{Results}

\section{Baseline characteristics}

Of 142 patients screened, 141 were eligible for the study. Four patients refused to give their consent, and 137 were randomized to receive levofloxacin $(n=65)$ or cefuroxime $(n=72)$. Eighty-eight percent of patients in the levofloxacin group and $86 \%$ of those in the cefuroxime group completed therapy. There was no statistically significant difference in dropout rates between the groups (Figure 1). Table 1 shows the baseline characteristics of the subjects. There was no notable difference between the two groups in terms of gender, age, smoking status, and severity of exacerbation.

\section{Clinical success rates}

Clinical response as evaluated by respiratory specialists at the second visit was comparable in both groups. Clinical success was achieved in $90.4 \%$ of patients in the levofloxacin group and $90.6 \%$ of those in the cefuroxime group. The minimum and maximum value for the $95 \%$ confidence interval of the difference between the groups was -9.40 and 10.91 , respectively, confirming that the clinical success rate of levofloxacin was not inferior to that of cefuroxime.

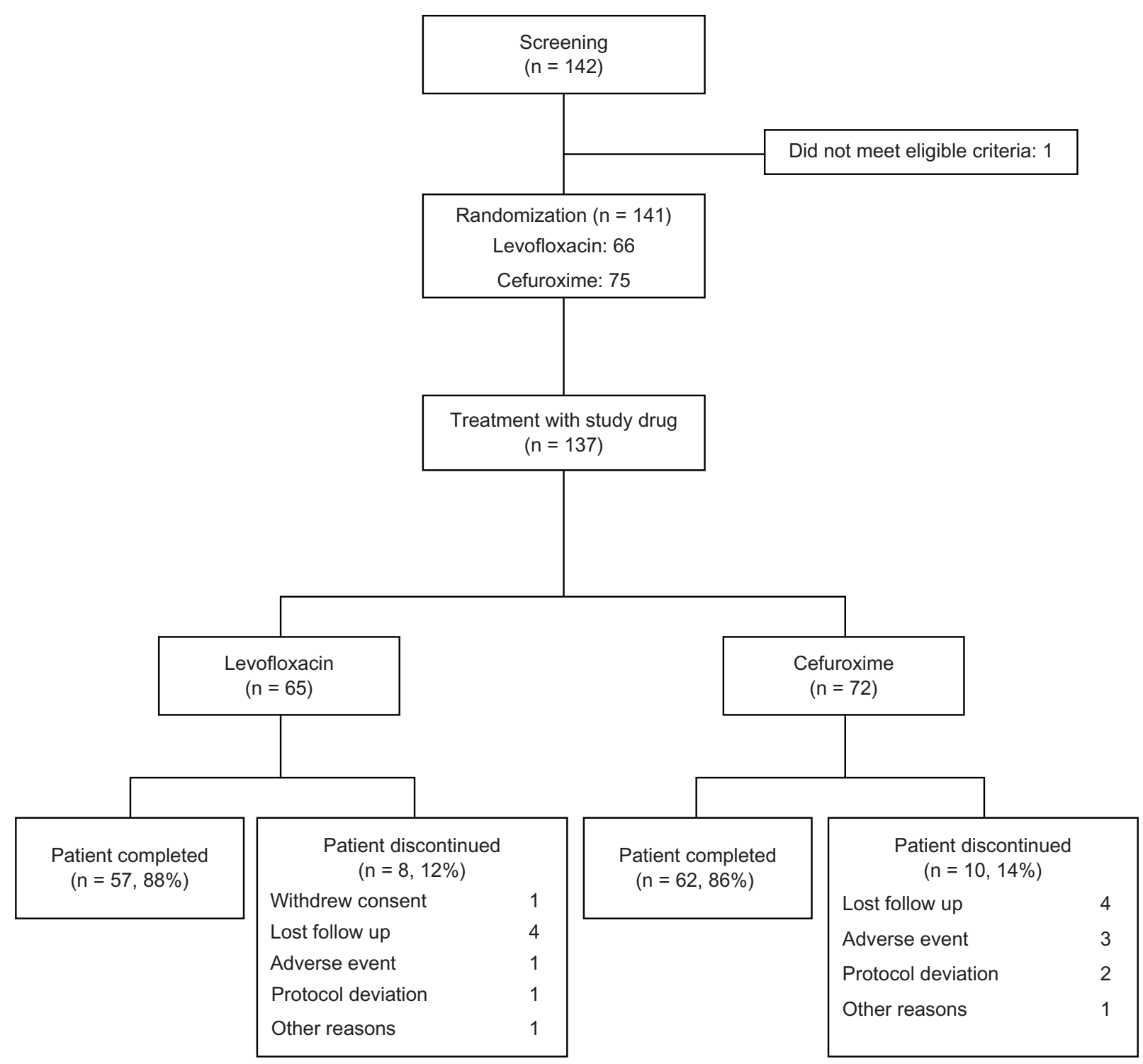

Figure I Scheme of study enrollment, randomization, and follow-up. 
Table I Characteristics of enrolled patients

\begin{tabular}{llll}
\hline Characteristic & $\begin{array}{l}\text { Levofloxacin } \\
(\mathbf{n}=65)\end{array}$ & $\begin{array}{l}\text { Cefuroxime } \\
(\mathbf{n}=\mathbf{7 2})\end{array}$ & P-value \\
\hline Male, n (\%) & $59(90.77)$ & $67(93.06)$ & 0.62 \\
Age, years (mean \pm SD) & $70.95 \pm 8.18$ & $69.63 \pm 8.30$ & 0.3 \\
Smoking, n (\%) & & & \\
$\quad$ Nonsmoker & II (16.92) & $7(9.72)$ & 0.1 \\
$\quad$ Ex smoker & $42(64.62)$ & $41(56.94)$ & \\
$\quad$ Smoker & I2 (18.46) & $24(33.33)$ & \\
Severity of exacerbation, n (\%) & & \\
$\quad$ Mild & $27(41.54)$ & $24(33.33)$ & $0.6 \mathrm{I}$ \\
$\quad$ Moderate & $27(41.54)$ & $34(47.22)$ & \\
$\quad$ Severe & II (16.92) & $14(19.44)$ & \\
\hline
\end{tabular}

Abbreviation: SD, standard deviation.

\section{Microbiologic efficacy rates}

Microbiologic efficacy rates were $85.7 \%$ in the levofloxacin group and $68.8 \%$ in the cefuroxime group (Table 3 ). However, because of the small number of patients who were available for evaluation, the difference was not statistically significant.

\section{Micro-organisms identified}

Table 4 shows the organisms identified in each group. Thirty-seven pathogens from 12 species were isolated. Of those, S. pneumoniae accounted for $40.5 \%$ (15 isolates), M. catarrhalis for $13.5 \%$ (five isolates), and Klebsiella pneumoniae for $10.8 \%$ (four isolates).

\section{Safety}

The safety evaluation was performed in all patients who were randomized and took the test medication. Side effects related to medication were found in three cases from each group. There were four cases of mild dyspepsia, one of headache, and one of insomnia. None were serious, and no death was reported because of side effects.

\section{Discussion}

We found that levofloxacin was not inferior to cefuroxime in terms of clinical response rate and safety in the

Table 2 Clinical success rates of both groups

\begin{tabular}{lll}
\hline & $\begin{array}{l}\text { Levofloxacin } \\
(\mathbf{n}=\mathbf{6 5})\end{array}$ & $\begin{array}{l}\text { Cefuroxime } \\
(\mathbf{n}=\mathbf{7 2})\end{array}$ \\
\hline $\begin{array}{l}\text { Clinical response, } \mathrm{n}(\%) \\
\quad \text { Cure }\end{array}$ & $20(34.48)$ & $22(34.38)$ \\
$\quad$ Improved & $33(56.90)$ & $36(56.25)$ \\
$\quad$ Failure & $5(8.62)$ & $6(9.38)$ \\
Clinical success rate, $\mathrm{n}(\%)$ & $53(91.38)$ & $58(90.63)$ \\
Treatment difference with 95\% Cl & $0.75 \%(-9.40,10.91)$ \\
\hline
\end{tabular}

Abbreviation: $\mathrm{Cl}$, confidence interval.
Table 3 Microbiologic efficacy rates of both groups

\begin{tabular}{|c|c|c|c|}
\hline Second return visit & $\begin{array}{l}\text { Levofloxacin } \\
(n=7)\end{array}$ & $\begin{array}{l}\text { Cefuroxime } \\
(n=16)\end{array}$ & $P$-value \\
\hline \multicolumn{4}{|c|}{ Microbiologic evaluation, n (\%) } \\
\hline Presumed eradication & I (I4.29) & $3(18.75)$ & \\
\hline Eradication & $5(71.43)$ & $7(43.75)$ & \\
\hline Presumed persistence & $0(0.00)$ & $I(6.25)$ & \\
\hline Persistence & I (I4.29) & $4(25.00)$ & \\
\hline Superinfection & $0(0.00)$ & $\mathrm{I}(6.25)$ & \\
\hline $\begin{array}{l}\text { Microbiologic efficacy } \\
\text { rate, } n(\%)\end{array}$ & $6(85.7 I)$ & II (68.75) & $0.62^{\mathrm{a}}$ \\
\hline
\end{tabular}

treatment of AECOPD. The findings of this study suggest that levofloxacin $500 \mathrm{mg}$ daily for seven days is at least as effective as cefuroxime $500 \mathrm{mg}$ daily for mild to moderate AECOPD and $1000 \mathrm{mg}$ daily for severe AECOPD. The microbiologic response seemed higher in the levofloxacin group, but because of the small number of patients in whom analysis was possible, this result was not statistically significant. The safety profiles of both groups were also comparable.

To our knowledge, this is the first study comparing the efficacy of levofloxacin and cefuroxime in the treatment of AECOPD. Previous studies comparing levofloxacin versus cefuroxime in treating exacerbations of chronic bronchitis have reported similar results. Shar et al have reported the results of their randomized double-blind study of levofloxacin versus cefuroxime in acute exacerbations of chronic bronchitis. ${ }^{24}$ In their study, three groups of patients (receiving levofloxacin $250 \mathrm{mg}$ or $500 \mathrm{mg}$ daily or cefuroxime $250 \mathrm{mg}$ twice daily) showed similar clinical success rates and tolerability. Petitpretz et al reported the results of another randomized clinical trial of levofloxacin $500 \mathrm{mg}$ daily versus

Table 4 Pathogens identified in sputum

\begin{tabular}{lll}
\hline & Levofloxacin & Cefuroxime \\
\hline $\begin{array}{l}\text { Subjects with identified } \\
\text { pathogens, } \mathrm{n}(\%)\end{array}$ & $13(20.00 \%)$ & 21 (29.17\%) \\
$\begin{array}{l}\text { Total number of identified } \\
\text { pathogens }\end{array}$ & 13 & 24 \\
$\quad$ Streptococcus pneumoniae & 6 & 9 \\
Klebsiella pneumoniae & 3 & $\mathrm{I}$ \\
Moraxella catarrhalis & & 5 \\
Enterobacter cloacae & & 3 \\
Acinetobacter baumannii & & 2 \\
Pseudomonas aeruginosa & $\mathrm{I}$ & $\mathrm{I}$ \\
Serratia marcescens \\
Haemophilus influenzae & $\mathrm{I}$ & $\mathrm{I}$ \\
Escherichia coli & $\mathrm{I}$ & \\
Klebsiella oxytoca & $\mathrm{I}$ & $\mathrm{I}$ \\
Enterobacter aerogenes & & $\mathrm{I}$ \\
Staphylococcus aureus & & \\
\hline
\end{tabular}


cefuroxime $250 \mathrm{mg}$ twice daily in patients with exacerbation of chronic obstructive bronchitis. ${ }^{25}$ The results of these studies are quite similar to ours, but our study demonstrated noninferiority of levofloxacin compared with cefuroxime also in AECOPD. Lastly, Ruiz-Gonzalez et al reported randomized trial of levofloxacin versus standard antibiotic therapy in AECOPD. ${ }^{26}$ The standard therapy included clarithromycin, cefuroxime, and amoxicillin-clavulanic acid. Patients in the levofloxacin group showed a reduction in hospitalization rate compared with those in the standard antibiotic group. Therefore, the results of our study not only confirm previous studies but confirm the noninferiority of levofloxacin over cefuroxime in AECOPD.

This was a multicenter study done in seven universityaffiliated hospitals, and all subjects were patients with COPD who had been previously diagnosed by spirometry.

However, it also has some limitations, in particular its nonblinded design. We cannot exclude the possibility that open-label treatment might have influenced our judgment of clinical efficacy and safety. A relatively small sample size is another shortcoming, in that studies of similar design to ours have had $600-800$ subjects. ${ }^{24,25}$ Our study was underpowered with regard to the primary outcome, so we cannot reach any conclusions regarding microbiologic response. The lack of a placebo arm is also problematic; however, because our study included patients with severe exacerbations, it would have been unsafe and unethical to include a placebo group. Having adopted a subjective measure of success, nonblinding could be another limitation.

The efficacy of an antimicrobial agent is determined by many factor, including regional antimicrobial resistance. South Korea, where this study was conducted, has a very high rate of antimicrobial-resistant respiratory pathogens. For instance, pneumococcal resistance to penicillin ranges from $60 \%$ to $75 \% .{ }^{27-29}$ Considering the fact that $S$. pneumoniae is the most frequent pathogen implicated in AECOPD, levofloxacin could be a more appropriate choice than macrolides or beta-lactams in treating AECOPD in Korea. In conclusion, levofloxacin is not inferior to cefuroxime in regard to clinical efficacy when treating AECOPD.

\section{Acknowledgment}

This study has been financially supported by Daiichi Sankyo Inc.

\section{Disclosure}

The authors report no conflicts of interest in this work.

\section{References}

1. Seemungal TAR, Donaldson GC, Bhowmik A, Jeffries DJ, Wedzicha JA. Time course and recovery of exacerbations in patients with chronic obstructive pulmonary disease. Am J Respir Crit Care Med. 2000;161: 1608-1613.

2. Donaldson GC, Seemungal TA, Bhowmik A, Wedzicha JA. Relationship between exacerbation frequency and lung function decline in chronic obstructive pulmonary disease. Thorax. 2002;57:847-852.

3. Pietila MP, Thomas CF. Inflammation and infection in exacerbations of chronic obstructive pulmonary disease. Semin Respir Infect. 2003;18:9-16.

4. Albertson TE, Louie S, Chan AL. The diagnosis and treatment of elderly patients with acute exacerbation of chronic obstructive pulmonary disease and chronic bronchitis. J Am Geriatr Soc. 2010;58:570-579.

5. Ram FS, Rodriguez-Roisin R, Granados-Navarrete A, Garcia-Aymerich J, Barnes NC. Antibiotics for exacerbations of chronic obstructive pulmonary disease. Cochrane Database Syst Rev. 2006;2:CD004403.

6. McCrory DC, Brown C, Gelfand SE, Bach PB. Management of acute exacerbations of COPD: a summary and appraisal of published evidence. Chest. 2001;119:1190-1209.

7. Saint S, Bent S, Vittinghoff E, Grady D. Antibiotics in chronic obstructive pulmonary disease exacerbations. A meta-analysis. JAMA. 1995;273:957-960.

8. Anthonisen NR, Manfreda J, Warren CP, Hershfield ES, Harding GK, Nelson NA. Antibiotic therapy in exacerbations of chronic obstructive pulmonary disease. Ann Intern Med. 1987;106:196-204.

9. Nouira S, Marghli S, Belghith M, Besbes L, Elatrous S, Abroug F. Once daily oral ofloxacin in chronic obstructive pulmonary disease exacerbation requiring mechanical ventilation: a randomised placebocontrolled trial. Lancet. 2001;358:2020-2025.

10. Daniels JM, Snijders D, de Graaff CS, Vlaspolder F, Jansen HM, Boersma WG. Antibiotics in addition to systemic corticosteroids for acute exacerbations of chronic obstructive pulmonary disease. Am J Respir Crit Care Med. 2010;181:150-157.

11. Woodhead M, Blasi F, Ewig S, et al. Guidelines for the management of adult lower respiratory tract infections. Eur Respir J. 2005;26: 1138-1180.

12. Monso E, Ruiz J, Rosell A, et al. Bacterial infection in chronic obstructive pulmonary disease. A study of stable and exacerbated outpatients using the protected specimen brush. Am J Respir Crit Care Med. 1995;152:1316-1320.

13. Pela R, Marchesani F, Agostinelli C, et al. Airways microbial flora in COPD patients in stable clinical conditions and during exacerbations: a bronchoscopic investigation. Monaldi Arch Chest Dis. 1998;53: 262-267.

14. Seemungal T, Harper-Owen R, Bhowmik A, et al. Respiratory viruses, symptoms, and inflammatory markers in acute exacerbations and stable chronic obstructive pulmonary disease. Am J Respir Crit Care Med. 2001;164:1618-1623.

15. Blasi F, Damato S, Cosentini R, et al. Chlamydia pneumoniae and chronic bronchitis: association with severity and bacterial clearance following treatment. Thorax. 2002;57:672-676.

16. Seemungal TA, Wedzicha JA, MacCallum PK, Johnston SL, Lambert PA. Chlamydia pneumoniae and COPD exacerbation. Thorax. 2002;57: 1088-1089.

17. Kolodziej MA, Jensen L, Rowe B, Sin D. Systematic review of noninvasive positive pressure ventilation in severe stable COPD. Eur Respir J. 2007;30:293-306.

18. Soler N, Torres A, Ewig S, et al. Bronchial microbial patterns in severe exacerbations of chronic obstructive pulmonary disease (COPD) requiring mechanical ventilation. Am J Respir Crit Care Med. 1998;157: 1498-1505.

19. Fagon JY, Chastre J, Trouillet JL, et al. Characterization of distal bronchial microflora during acute exacerbation of chronic bronchitis. Use of the protected specimen brush technique in 54 mechanically ventilated patients. Am Rev Respir Dis. 1990;142:1004-1008. 
20. Miravitlles M, Espinosa C, Fernandez-Laso E, Martos JA, Maldonado JA, Gallego M. Relationship between bacterial flora in sputum and functional impairment in patients with acute exacerbations of COPD. Study Group of Bacterial Infection in COPD. Chest. 1999;116:40-46.

21. Eller J, Ede A, Schaberg T, Niederman MS, Mauch H, Lode H. Infective exacerbations of chronic bronchitis: relation between bacteriologic etiology and lung function. Chest. 1998;113:1542-1548.

22. Sin DD, McAlister FA, Man SF, Anthonisen NR. Contemporary management of chronic obstructive pulmonary disease: scientific review. JAMA. 2003;290:2301-2312.

23. Quon BS, Gan WQ, Sin DD. Contemporary management of acute exacerbations of COPD: a systematic review and metaanalysis. Chest. 2008;133:756-766.

24. Shah PM, Maesen FPV, Dolmann A, Vetter N, Fiss E, Wesch R. Levofloxacin versus cefuroxime axetil in the treatment of acute exacerbation of chronic bronchitis: results of a randomized, doubleblind study. J Antimicrob Chemother. 1999;43:529-539.
25. Petitpretz P, Chone C, Tremolieres F. Levofloxacin $500 \mathrm{mg}$ once daily versus cefuroxime $250 \mathrm{mg}$ twice daily in patients with acute exacerbations of chronic obstructive bronchitis: clinical efficacy and exacerbation-free interval. Int J Antimicrob Agents. 2007;30:52-59.

26. Ruiz-Gonzalez A, Gimenez A, Gomez-Arbones X, et al. Open-label, randomized comparison trial of long-term outcomes of levofloxacin versus standard antibiotic therapy in acute exacerbations of chronic obstructive pulmonary disease. Respirology. 2007;12:117-121.

27. Chong Y, Lee K, Park YJ, et al. Korean Nationwide Surveillance of Antimicrobial Resistance of bacteria in 1997. Yonsei Med J. 1998;39: 569-577.

28. Song JH. Emergence and spread of antimicrobial resistance of Streptococcus pneumoniae in Korea. Yonsei Med J. 1998;39: 546-553.

29. Baquero F. Pneumococcal resistance to beta-lactam antibiotics: a global geographic overview. Microb Drug Resist. 1995;1:115-120.

\section{Publish your work in this journal}

The International Journal of COPD is an international, peer-reviewed journal of therapeutics and pharmacology focusing on concise rapid reporting of clinical studies and reviews in COPD. Special focus is given to the pathophysiological processes underlying the disease, intervention programs, patient focused education, and self management protocols.

\section{Dovepress}

This journal is indexed on PubMed Central, MedLine and CAS. The manuscript management system is completely online and includes a very quick and fair peer-review system, which is all easy to use. Visit http://www.dovepress.com/testimonials.php to read real quotes from published authors. 